Article

\title{
Entropic Citizenship Behavior and Sustainability in Urban Organizations: Towards a Theoretical Model
}

\author{
David Coldwell \\ School of Economic and Business Sciences, University of the Witwatersrand, Private Bag1, Wits, \\ Johannesburg 2050, South Africa; david.coldwell@wits.ac.za; Tel.: +27-11-717-0000 \\ Academic Editors: Pedro Cabral and Alexander Zamyatin \\ Received: 1 November 2016; Accepted: 14 December 2016; Published: 19 December 2016
}

\begin{abstract}
Entropy is a concept derived from Physics that has been used to describe natural and social systems' structure and behavior. Applications of the concept in the social sciences so far have been largely limited to the disciplines of economics and sociology. In the current paper, the concept of entropy is applied to organizational citizenship behavior with implications for urban organizational sustainability. A heuristic is presented for analysing personal and organizational citizenship configurations and distributions within a given workforce that can lead to corporate entropy; and for allowing prescriptive remedial steps to be taken to manage the process, should entropy from this source threaten its sustainability and survival.
\end{abstract}

Keywords: entropy; organizational systems; organizational entropy; organizational citizenship entropy; sustainability

\section{Introduction}

Bailey [1], in his description of social entropy theory, postulates that "order is not a constant value but a matter of degree. Order can vary from a low of zero (randomness or maximum entropy) to a high of perfect predictability (maximum departure from randomness or minimum entropy)". Total organizational unsustainability in the current paper is regarded as arising when Organizational Citizenship Behavior (OCB) deconstructs into Entropic Citizenship Behavior (ECB) which is characterized by low orderliness and minimum predictability in behavior. The disorder created by extreme personal and organizational supportive behavior is inimical to effective organizational outcomes and goal attainment and thus, ultimately, its sustainability. In the former situation, excessive supportive (helping) behavior concentrated among specific personnel categories derails organizational sustainability by its disorderly fragmentation and retraction of work behavior from focused performance and formal goal attainment. In the latter situation, excessive formal organization supportive behavior (i.e., going to extremes to attain formal organizational performance goals) leads to the derailment of formal goal attainment by disorder created by extreme work behavior that ultimately is inimical to the attainment of such goals.

\section{The Origins of the Concept of Entropy and Its Applications in Science: A Brief Overview}

The concept of entropy originated in the natural sciences and has only much more recently been applied in the social sciences, including economics, sociology and to a limited extent, management. A common thread in the literature relating to the concept of entropy, despite the fact that it has been used in many different contexts with different meaning attached to it, is the idea that it embodies disorder and "lost" energy. An eclectic selection of some main entropy theories from various disciplines is presented in the following sections. 


\subsection{Entropy in Natural Science}

The concept of entropy was first conceived in 1867 by Clausius [2], who formulated the Second Law of Thermodynamics. The First law being that energy is not created or destroyed and the Third Law that absolute zero can never be achieved. Entropy, derived from the Greek en+tropein meaning "transformation content", was regarded by Clausius [2] as that fraction of energy contained in the system unavailable to produce work; and in any system, this unavailable energy tends to increase. Entropy is usually defined in closed systems in which energy cannot be added or removed from the system. Although the total amount of energy that becomes disordered and is unavailable again in that system increases, it does not prevent order somewhere else in the same system from increasing [3].

Boltzmann [4] applied the concept of Entropy to statistical mechanics. Boltzmann's entropy is defined as:

$$
S=K \text { in } W
$$

where $K$ is the Boltzmann constant unit of measurement of entropy, $W$ is the thermodynamic probability (statistical weight) and incorporates the total number of microscopic states compatible with the macroscopic state of the system. $W$ is the degree of disorder or amount of disorder in the system and $S$ is Entropy which is a positive increasing function of disorder $(W)$ [5].

Shannon [6] conceptualized information entropy as measurable in terms of "negentrophy", where information $=-$ entropy (negentrophy). Gell-Mann [7] suggests that entropy and information are closely related in so far as entropy can be seen as a measure of ignorance. Gell-Mann [7] suggests entropy can be regarded as a measure of ignorance in a given system and that the entropy of a microstate of a given system can be measured in terms of the degree of ignorance of the microstates of which it is constituted.

Theil [8] adopts Shannon's conceptualization of entropy as a measure of dividedness and dispersion in the development of his "evenness of spread" entropy concept. It is regarded as providing a platform for the development of a formal model of organizational citizenship entropy in the current paper. However, it should be noted that "evenness of spread" is not synonymous with homogeneity and is rather a measure of heterogeneity in microstates comprising a given system.

Landsberg [9], presented a simple order/disorder entropy theory based on thermodynamics and information theory which defines entropy (total disorder) in a system as arising when the system's capacity for disorder is 'overwhelmed' by its capacity for absorbing further information.

\subsection{Entropy in Social Science}

In the disciplinary field of Sociology, Bailey [1] gives a description of social entropy theory and postulates that "order is not a constant value but a matter of degree. Order can vary from a low of zero (randomness or maximum entropy) to a high of perfect predictability (maximum departure from randomness or minimum entropy)". It can clearly be derived from this quotation that in zero order (maximum entropy) social systems, there will be maximum energy wastages. Conversely, in social systems with minimum departures from randomness, there will be minimum energy wastages, or energy lost to these systems. This idea is adopted in relation to organizational entropy discussed in the following section.

\subsection{Organizational Entropy}

Gunn [10] defined business thermodynamics as the transformation of energy in a productive system and constitutes the essence of human motivation. The transformation of energy central to business dynamics was derived from Le Chatelier's Principle [11] that: "Every change of one of the factors of an equilibrium occasions a rearrangement of the system in such a direction that the factor in question experiences a change in a sense opposite to the original change". Corporate entropy is regarded as the portion of a system's energy that is unable to be transformed into functional work and is irreversibly lost from the system. 
Ackoff [12] regarded corporate entropy as being reduced by eliminating the wastage of corporate energy. If, for example, an executive manager uses his extra-board meeting time in a way that stimulates and motivates his subordinates to increase work outputs, he will have reduced corporate entropy. Ackoff calculates from empirical data that company Boards meet for around $4 \mathrm{~h}$ and that an executive would sit on ten or less Boards each meeting once a month. Ackoff's [12] calculates that an executive manager would spend about 40 hours on Board meetings per month, which is around $25 \%$ of the time they spend at work. Ackoff [12] suggests that there is ample time for executive managers to focus their energies in planning and coordinating work activities of employees, and that this coordinating activity is able to tap into energy normally wasted in worry and disorganized "fire-fighting". By redirecting wasted energy to productive uses, corporate entropy is reduced.

DeMarco and Lister [13] define corporate entropy as "levelness or sameness" and the more sameness increases, the less the potential to create energy to do work. Uniformity in attitudes and thought processes in a corporation is seen as entropy because this has a tendency to smother productive energy at work. They maintain that entropy in organizations is brought about by the inevitable increase in staleness and stasis one finds in older corporations with tightly structured bureaucracies.

Williams [14] defines organizational entropy as the disorder or randomness in which work functions are organized and performed. Williams [14] suggests that in organizations with multiple hierarchies corresponding to the number departments and functions it incorporates and dependent on size, poorly organized work functions lead to disorder and entropy. Williams [14] maintains that in many organizations, there is randomness as to how work is performed in multiple on-going projects requiring multi-skilled collaboration. For example, person $\mathrm{A}$ is working on project $\mathrm{Y}$ and needs person $B$ 's skills. However, person $B$ is working on project $X$ at that time so project $Y$ is held up. In a large organization with many projects being processed simultaneously, such disorder in energy utilization leads to energy wastage and entropy.

A common factor underlying the above interpretations of organizational entropy by different authors is that it relates to disorder and wastage.

\subsection{Organizational Systems Entropy}

A recent paper by Martínez-Berumena, López-Torresa and Romo-Rojas [15] develops a method to evaluate entropy in organizational systems. Martínez-Berumena et al. [15] define an organizational system as " ... a combination of assembled and interconnected elements, forming an organization set, which have a defined goal, and are immersed in an environment with which they interact. Since organizational design and management integrates various factors and perspectives, both internal and external, including technical and technological, cultural, social, political and economic, it is possible to apply a systems approach, and systems engineering concepts to study this (sic) kind of systems". Lara Rosano [16] maintains that a "system" exists when elements composing the system (such as processes, people, information, facilities, services, etc.) are related; each element within the system has a bearing on function of the system as a whole, and the system as a whole is affected by the interaction of at least two elements that compose it.

Systems can be regarded as open or closed. Closed systems do not interact with their environments, whereas open systems, " ... interact strongly with their environment, as it get supplies from it and performs its duties or send its products to it. Open systems are extremely complex; this classification includes living beings, as well as economic, technological, social or organizational systems. If we also consider that these systems have one or more purposes, their complexity increases considerably". [15]. Organizations' business or otherwise in the urban environment can be considered complex systems. A complex system can be regarded as being composed of dynamic, interacting and organized hierarchies with non-linear outcomes [15]. Simon [17] indicates that complex systems are omnipresent in urban environments and include organizations such as businesses, universities, churches, municipal administrative offices and governments. 


\section{The Concept of Organizational Citizenship Entropy}

Organizational Citizenship Behavior (OCB) is defined by Organ [18] as: "individual behavior that is discretionary, not directly or explicitly recognized by the formal reward system". OCB is further defined by Organ [19] as, "contributions to the maintenance and enhancement of the social and psychological context that supports task performance (or the technical/technological/production system)". Organ's [19] definition of OCB as a phenomenon that extends beyond individual to group level has multiple implications for the importance of OCB for organizational sustainability. Two core aspects of Organ's [19] definition of OCB as a group-level phenomenon emerge from his analysis; the conception of "individual" "conscientiousness" and the conception of "group morale". Although not specifically mentioned by Organ [19], it seems reasonable to suggest that group morale arises largely from the collective of individual conscientiousness and is a major aspect of OCB. At the individual level of analysis, OCB is typically regarded as multifaceted, incorporating altruism, compliance, sportsmanship, courtesy, and civic virtue. However, OCB is regarded as a generalized concept that can be conceived essentially as a dichotomy consisting of organizational and personal support dimensions [20].

Findings of OCB empirical studies [21,22] suggest that a balance between personal and organizational goals in organizational citizenship is desirable for good organizational performance and that extremes of either aspect may reduce organizational sustainability. From the theoretical point of view, it is maintained in the current paper that increasing amounts of either personally or organizationally oriented OCB distributed unequally amongst categories of organizational personnel will result in decreases in organizational sustainability. The limiting cases offered by the empirical data obtained from military history and some recent business occurrences [23] do in fact suggest that that high levels of either personal or organizational behavior lead to ECB situations of instability and unpredictability that undermine the attainment of formal organizational goals, when they become unequally distributed in units or categories of personnel throughout particular organizations. It follows that the more Entropic Citizenship Behavior (ECB) becomes a group level phenomenon in departments constituting an organization, the greater threat it is to the achievement of its goals and its ultimate sustainability. Very briefly, Coldwell and Callaghan [23] in their study of organizational citizenship behavior, found examples from military history and business of the negative effects of extreme forms of personal or organizational citizenship behavior on organizational performance. Examples of fraternization with the enemy in the First World War where British and German frontline soldiers on both sides became involved in initiating non-lethal war activities that acted out belligerence without harmful intent Axelrod [24] demonstrated the effects of extreme personal oriented citizenship behavior where care for survival overrode the Militia's goal on both sides to wage aggressive and lethal warfare to destroy the enemy. Extreme forms of organizational citizenship behavior, inimical to the survival of the organization, are also evident in the case of Japanese Kamikaze pilots in the Second World War. In this case, the goal of the Japanese high command was to win the war by any means available to it, even if this meant deliberate suicide missions by their airmen in aircraft laden with explosives on particular enemy targets. Initially, such missions were carried out by young men who had volunteered to sacrifice their lives for their country, but later, the difficulty in finding pilots to do this off their own volition led the Japanese high command to commandeer young men to perform this sacrifice. Reluctance to die for this cause became so great that Japanese commanders had to bolt down the canopies of the aircraft of the men forced to fly these one-way missions to eternity [25]. Again, this extreme form of citizenship behavior became inimical to the Japanese war effort and their prospect of winning it. Not only were the suicide missions generally unsuccessful in doing any appreciable damage to the enemy, they eventually undermined the sustainability of the military. General Japanese morale collapsed to the extent that Japanese military recovery after the war was considerably delayed [25].

Examples of extreme forms of organizational and personal citizenship behavior in the business environment are also evident. An example of extreme organizational citizenship behavior in business organizations is Kohler, the CEO of Ricola's recent suicide committed to eliminating personal dishonour and limiting damage to the company's reputation when he confessed to fraud [26]. On the other hand, 
voluntary pay cuts by CEOs such as the action by Ornstein CEO of Mesa Air Group in 2009 can be regarded as an extreme form of personal (helping others) support behavior. Such extreme personal citizenship behavior, far from supporting the organization, may result in reductions in its effectiveness and sustainability.

In broad terms, Entropic Citizenship Behavior (ECB) occurs when personal or organizational oriented OCB is unevenly spread in departments throughout the organization. On the one hand, high personal oriented helping OCB amongst employees in an organization is likely to reduce employee competitiveness and deflect impetus for achieving organizational goals. On the other hand, high organizational oriented OCB is likely to generate employee "burnout" through its fixation on productivity. Both these extreme forms of OCB are threats to organizational sustainability.

Nielsen, Hrivnak and Shaw [21] point out in their meta-analysis that only three percent of 400 studies of the OCB-performance relationship conducted since 1983 have considered OCB as a group level phenomenon. Although clearly this suggests that OCB-performance relationship as a group level phenomenon requires further empirical analysis in its own right, the need for a theoretical model with particular focus on the effects of organizational sustainability (an aspect of successful performance durability) in conditions of organizational citizen behavioral entropy (where performance is likely to be seriously negatively affected) is also indicated.

Before introducing the proposed entropy model of OCB-sustainability, the concept of organizational "sustainability" in urban contexts is discussed in the following section.

\section{The Concept of Sustainability}

The concept of organizational sustainability is often regarded in terms of the triple bottom line of economic, social and environmental factors which, in this respect, could be seen as a failure of economic survival, its most fundamental requirement. There can be no social or environmental repercussions, positive or negative, if an organization is unable to survive economically. Also, in organizations, including those that are not specifically business concerned, the loss of organizational sustainability may affect future generation's ability to meet their own needs. For example, the decimation of military organizations in war, such as that experienced by Japan at the end of the second world war-which was at least partly attributable to the extreme forms of organizationally-oriented citizenship behavior adopted in military mobilization and strategy practiced at that time (such as that evidenced in suicide attacks that became prominent in the final months of the war)—created military organizational entropy that made future Japanese generations incapable of effectively meeting their own defensive needs and dependent on the protection of foreign states.

\section{Strong and Weak Sustainability}

The literature on strong and weak sustainability in urban organizations is used in two distinct ways relating to different and specific disciplinary perspectives. On the one hand, the environmental disciplinary perspective refers to sustainability in terms of environmental natural capital; on the other hand, that of the economic disciplinary perspective refers to economic "manufactured" capital of goods and services. When these two disciplinary perspectives are brought together, the core issue of concern between the two spheres becomes substitutability between the economic and the environmental factors. As Ayres et al. [27] put it:

"Much of the confusion in the discussion of strong sustainability arises from a failure to distinguish between the two assumptions dividing weak and strong sustainability. The first is the assumption of substitutability between natural and manufactured capital. The second is that economic well-being "covers" all other concerns. If the second assumption is accepted (as it sometimes is by advocates of strong sustainability) then the argument about substitutability boils down to a purely economic debate about elasticities of substitution, technological advance and so on. If, on the other hand, substituting financial capital for natural resources is incompatible with maintaining a suitable physical environment 
for the human species, then strong sustainability implies that we must step outside the conventional market framework in order to establish the conditions for maintaining human happiness."

Ayres et al.'s comment suggests that strong sustainability should take the necessity of maintaining a natural environment suitable for human existence as non-negotiable in any proposed substitution for manufactured economic capital. Strong sustainability is considered more than simply economic capital development, particularly if this impinges on non-negotiable aspects of natural capital. Perspectives on sustainability that focus purely or largely on economic capital are regarded by Ayres et al. [27] as weak sustainability. This is because such a perspective incorporates an overriding concern to increase manufactured capital even when such development results in the destruction of natural environmental resources, particularly those essential for human survival. An oft quoted example of the implications of weak sustainability advocating unbridled growth in economic capital to the detriment of natural resources is provided by the catastrophic effects it incurred on the small Pacific island of Nauru [28]. It was discovered on the island of Nauru in 1900 that it contained one of the richest deposits of phosphate in the world. By 1999, the island's natural environment was almost destroyed by over ninety years of continuous mining. In a kind of apparent 'substitution' for this ecological devastation, islanders have benefited from high per capita income for several decades allowing them to establish a trust fund of around 1 billion US dollars. Unfortunately, however, the Asian financial crisis destroyed the trust fund and today Nauruans have nothing to show for the sacrifice of their natural environment and the ecological disaster that continuous mining generated on the island. Nauru islanders' sorry experience clearly illustrates the core problem that a weak sustainability perspective entails that of the complete destruction of the natural environment and the exhaustion of non-renewable natural resources. In these circumstances, the substitution of natural for economic capital presents a one-way, irreversible strategy that offers no return once it is embarked on.

Strong sustainability, on the other hand, promotes the prospect of non-diminishing life opportunities in the forms of natural, social and environmental capital accumulation. Natural resources are essential both for economic production and the sustenance of human life and welfare. They cannot, therefore, be fully substituted by manufactured capital. Even on purely economic grounds, therefore, the argument for weak sustainability becomes conceptually and practically untenable. On moral and ethical grounds, weak sustainability also becomes problematical. Perhaps the most fundamental human moral motive and behavioral rationale is that of altruistic concern and awareness of others' needs. This suggests that the destruction of natural resources and diminishing or eradicating entirely their use for future generations, may not only deprive them of the opportunity for sustained economic development, but also eliminate the propensity for production and human life altogether.

Ultra strong sustainability which promotes the intrinsic right of nature to exist unmolested by human intervention is advocated by the Deep Ecology group. Ayres et al. [27] point out that the objective of an unmolested natural environment is impossible for two fundamental reasons. First, the sustainability of current global economic structures and the quality of human life itself depends on natural resources. Second, ecosystems themselves are continuously in a state of fluctuation of being born, maturating and dying off, even without human intervention. Also and insufficiently recognized by the Deep Ecology movement is the fact that humans themselves are an integral part of nature. Thus, Ayres at al. [27] advocate a "compromise" approach in strong sustainability that recognizes the intrinsic need to preserve natural resources necessary for life-support, those required for economic production and those also that hold unique and irreplaceable natural value.

The concept of capital is defined by Neumayer [29] as, "stock that provides current and future utility" and natural capital as capital that endows human beings with "material and nonmaterial utility" [29]. Man-made capital includes, for example, technology, factories, railways and roads. Human capital is a distinct capital that encompasses human knowledge as a whole [29].

Davies [30] maintains that natural capital consists of critical, constant and tradeable dimensions. Critical capital is capital that sustains human life. It includes the earth's atmosphere, its protective 
ozone layer, and rare species under threat of extinction. Once gone or irreversibly damaged, critical capital cannot be restored. Constant capital is natural capital which is important but that can be relatively easily substituted, for example, the substitution of a forest by a nature park. Finally, tradeable capital is capital not highly valued in its own right and can be readily substituted or replaced.

The concept of weak sustainability, or sustainability that regards natural and man-made capital as freely substitutable, is based on the work of Solow [31-33] and Hartwick [34-36]. Weak sustainability maintains that man-made capital is of greater importance than natural capital and can easily substitute it. Strong sustainability, in contrast, recognizes that natural capital is sometimes not substitutable by man-made capital and in the case of critical capital, can never be substituted by it if humans are to survive. The concept of strong sustainability is used in the current paper as its conceptual point of departure. Baker [37] views the concepts of weak and strong sustainability as incorporating dynamics that change over time. The idea led to the development of the Environmental Kuznets Curve (EKC) which is portrayed as an inverted U-shaped curve with pollution on the vertical and per-capita income on the horizontal axes. The EKC suggests that there is a direct positive relationship between pollution and economic development that reaches a turning point through the greater environmental awareness and action of people and organizations today in reducing pollution while allowing economic development to proceed. This "enlightenment" in public attitude towards pollution occurred in the West after the Second World War as a result of apocalyptical publications such as Carson's [38] "Silent Spring" on the effects of pollution on fauna in particular, and Shute's [39] "On the beach" novel about the effects of nuclear fall-out. The EKC curve plots the progression over time from strong to weak sustainability and thence, from the turning point after the Second World War, from weak to strong sustainability.

It could be said that weak sustainability generates entropy in organizational systems in the organizational system and that the aggregated accumulation of entropy in microstate urban organizational systems can ultimately lead to the unsustainability of urban macrostates. Heylighens [40] suggests that for dissipative systems such as business organizations operating in the urban environment to be stable, internal heterogeneities need to be maintained so that the systems evolve towards higher-order states. Without this progression, systems degenerate and homogenize with the disordered environment. Thus, entropy can be regarded as an indicator of the sustainability of organizational systems in the urban environment. Strong sustainability which is sensitive and open to changing economic, social and environmental conditions as described earlier, equips organizational systems for intergenerational survival by reducing their entropic tendencies. Sustainability in organizational systems has been recently delineated by Martínez-Berumena et al. [15] in relation to organizational information's "maturity", "organizational integration" and "results orientation". Martínez-Berumena et al. [15] incorporate the Viable Systems Model (VSM) devised by Beer [41] in measuring 11 factors they identify as determining organizational system sustainability, namely: innovation, talent, culture, leadership, structure, information and internal communication, management and internal control, competitive monitoring, execution, strategy, and governance. Each of the eleven factors is measured in terms of its maturity (extent to which a factor is developed and systematically applied), organizational integration (degree to which a factor is shared and interacts with other organizational functions throughout the organization) and results orientation (the alignment of each factor with the overall performance of the organization either by increasing the value generated by the organization, or by increasing its general performance and productivity).

Although an important advancement in the extant research literature on organizational systems entropy, Martnez-Berumena et al.'s [15] model includes very broadly defined categories, such as "leadership" and "culture", that tend to underplay the pervasive effects of specific aspects within such categories in the organization that can generate organizational entropy. For example, the category of "culture" is a very complex multi-faceted category that is difficult to measure using ten-point "risk index" in which low knowledge (greater ignorance) regarding the variation of critical organizational variables is regarded as implying a higher risk of entropy. 


\section{The Development of a Model of Organizational Citizenship Entropy}

The original model proposed by Coldwell and Callaghan [23] for OCB, ECB and organizational effectiveness followed the logic of the Laffer curve. The Laffer curve proposes that at tax rates of $0 \%$ and $100 \%$, government collects zero tax revenue. At zero taxation, there will be no tax revenue and at $100 \%$ tax, no one would be willing to work. In the former situation, no government would exist and anarchy would prevail. In the latter situation, there would be no money economy but a barter exchange process in place [42].

The heuristic originally proposed as ECB [23] follows the basic logic of the Laffer curve. The OCB, ECB organizational effectiveness heuristic suggests that at very high levels of personally oriented citizenship behavior and very low levels of organizationally oriented citizenship behavior, a situation of ECB will emerge. However, the heuristic is unable to articulate formally the distribution of personal and organizational citizenship behavior that leads to ECB. It is maintained in the current paper that Theil's [8] "evenness of spread" concept can provide the basis for a sounder, more formal and detailed development of the original Coldwell and Callaghan [23] model. Theil [8] uses Shannon's notion of entropy as a measure of dividedness and dispersion more broadly in his development of his "evenness of spread" entropy concept, and provides the basis of the development of a more formal model of organizational citizenship entropy. Evenness of spread is not synonymous with homogeneity and in fact denotes heterogeneity with each category. As briefly indicated earlier, Theil's concept focuses on the proportion of the maximum possible dispersion in which a variable is spread among categories or spatial units. This will be 1 if the variable is evenly spread among all categories and 0 if the variable is concentrated in a small number of categories. It is expressed by Equation (1)

$$
H n=\frac{\sum_{1}^{n} p_{1} \log \left(1 / p_{1}\right)}{\log n}
$$

Where $H n$ is the extent of entropy, and $p\left(x_{1}\right)$ is the probability of variable $x$ being found in each $n=1$, $\ldots, n$ zones, classes or categories.

The term "categories" in this paper, refers to an organization's divisional and departmental personnel. When either personal or organizational oriented citizenship behavior is concentrated among personnel in particular departments and not distributed evenly among such personnel that make up the organization as a whole, those departments tend towards entropy. This is similar to Iceland's [43] approach to spatial racial segregation in which the entropy index varies between 0 , when all areas have the same composition (i.e., maximum integration), to a high of 1 , when all areas contain one group only (maximum segregation).

The maximum level is given by the natural log of the number of groups used in the calculations. With six departments, the maximum entropy is $\log 6$ or 1.792. The maximum score occurs when all groups have equal representation in a particular organization, such that with six groups each department comprises about 17 percent of the organization's work force. Ceteris paribus, the greater the aggregated number of departments in an organization with unevenly distributed proportions of personal and organizational oriented citizenship behavior among individual personnel (for simplicity, evenness can defined as 50\% personal and 50\% organizational citizenship behavior in each individual, although this will vary in accordance with departmental and organizational functional objectives and individual predilection), the greater the tendency towards organizational entropy and corporate unsustainability. Conversely, the greater the aggregated number of departments in an organization with evenly distributed proportions of personal and organizational citizenship behavior among individuals, the lesser the tendency towards entropy and the greater the tendency toward corporate sustainability. Concentrations of organizational and personal citizenship behavior may reside in particular departments in the organization and at different levels on the organizational hierarchy. Thus, the Human Resources department may have high levels of personal oriented citizenship behavior while the Sales department may have high levels of organizationally oriented personnel. These differential 
organizational citizenship behaviors may complement each other and sustain the organization's profitability, however if aggregated citizenship behavior shows extremes in personal or organizational citizenship orientations among personnel, the organization is headed toward entropy.

Of course, many other factors are involved in the sustainability of an urban organization apart from evenness of spread of organizational citizenship behavior throughout the organization. Furthermore, as we have seen, specific concentrations of personal or organization oriented OCB among key individuals, such as CEOs can have apocalyptic effects on organizational sustainability. As in the case of Theil's [8] concept of segregation, many other factors aside from racial spatial distribution in urban communities are involved in explaining the phenomenon of racial segregation and its causes and potentially entropic consequences, if we take that to mean in this context, chaos and inter-racial strife. Fistola [44] maintains that cities are experiencing uncontrollable levels of entropic growth associated with specific human activities. Fistola [44] suggests that a crisis has emerged through entropy arising within single urban subsystems which promote ripple entropy effects in other urban subsystems and ultimately, the city as a whole. Fistola [44] argues that each single subsystem has the propensity to act as an "entropic generator" that initiates a path of destruction that can lead to the collapse of an entire city. The urban system is conceptualized as consisting of five interdependent subsystems: the geomorphological subsystem consisting of the ecosystem and territory; the anthropic subsystem comprising urban groups and individual actors; the functional subsystem incorporating human activities in urban space; the physical system involving material factors such as buildings and equipment; and the perceptive system consisting of the city's public image. Fistola [44] suggests that if the five urban subsystems are balanced, cities would maintain a sustainable dynamic state. However, imbalances from their normal states can act as entropy generators inimical to urban sustainability. Fistola [44] explains the mechanism of entropy generation between subsystems as a process of deconstruction in entropy clusters that systematically remove energy from specific subsystems necessary for continued survival.

Fistola's [44] notion of "enropic generator" and the potential effect of one subsystem on another, has particular relevance to the current paper. The suggestion that a singular entropic subsystem has propensity to generate entropy in other subsystems from particular human activities is important in indicating the wider repercussions and implications of OCE.

The basic model of organizational citizenship entropy is indicated diagrammatically in Figure 1. The U-shaped curve has organizational sustainability on the vertical axis and levels of personal and organizational-oriented citizenship behavior on the horizontal axis. The evenness/unevenness of the OCB distribution is indicated in Figure 1 as ranging from 0 (absolute uniformity) to $\mathrm{H}$ (absolute chaos). Figure 1 indicates that points beyond $\mathrm{H}_{\text {Min }}$ become increasingly even in OCB and towards absolute uniformity at point 0 . Figure 1 also indicates that beyond points $\mathrm{H}_{\mathrm{Max}}$, OCE emanating from increasingly uneven distributions in personal or organizational citizenship behavior become prominent. Figure 1 indicates $\mathrm{H}_{\mathrm{Max}}$ and $\mathrm{H}_{\mathrm{Min}}$ areas for both organizational and personal oriented OCB.

$\mathrm{H}_{\text {Min }}$ areas in the diagram denote areas of order among departments and divisions in the organization (evenness of OCB distribution) and are associated with high levels of organizational sustainability as such OCB balances increase productivity and long-term survival. Conversely, increasing imbalances in personal and organizational OCB occur towards $\mathrm{H}_{\mathrm{Max}}$ which, beyond that point and towards $\mathrm{H}$, become OCE threatening organizational sustainability. Increasing evenness in OCB distribution in the organization promotes sustainability. However, beyond $\mathrm{H}_{\text {Min }}$ and towards 0 , evenness in OCB distribution becomes problematical by reducing the organization's ability to adapt to changing contextual urban circumstances and functional needs for sustainability. However, as Cabal et al. [45] point out with regard to entropy in urban systems, there are a range of values in OCE distributions in an organization that can exist without compromising efficiency or sustainability. The model in Figure 1, however, clearly suggests that organizations that become unsustainable as a result of organizational citizenship entropy, will not be able to meet current or future economic, social or environmental generational needs. 


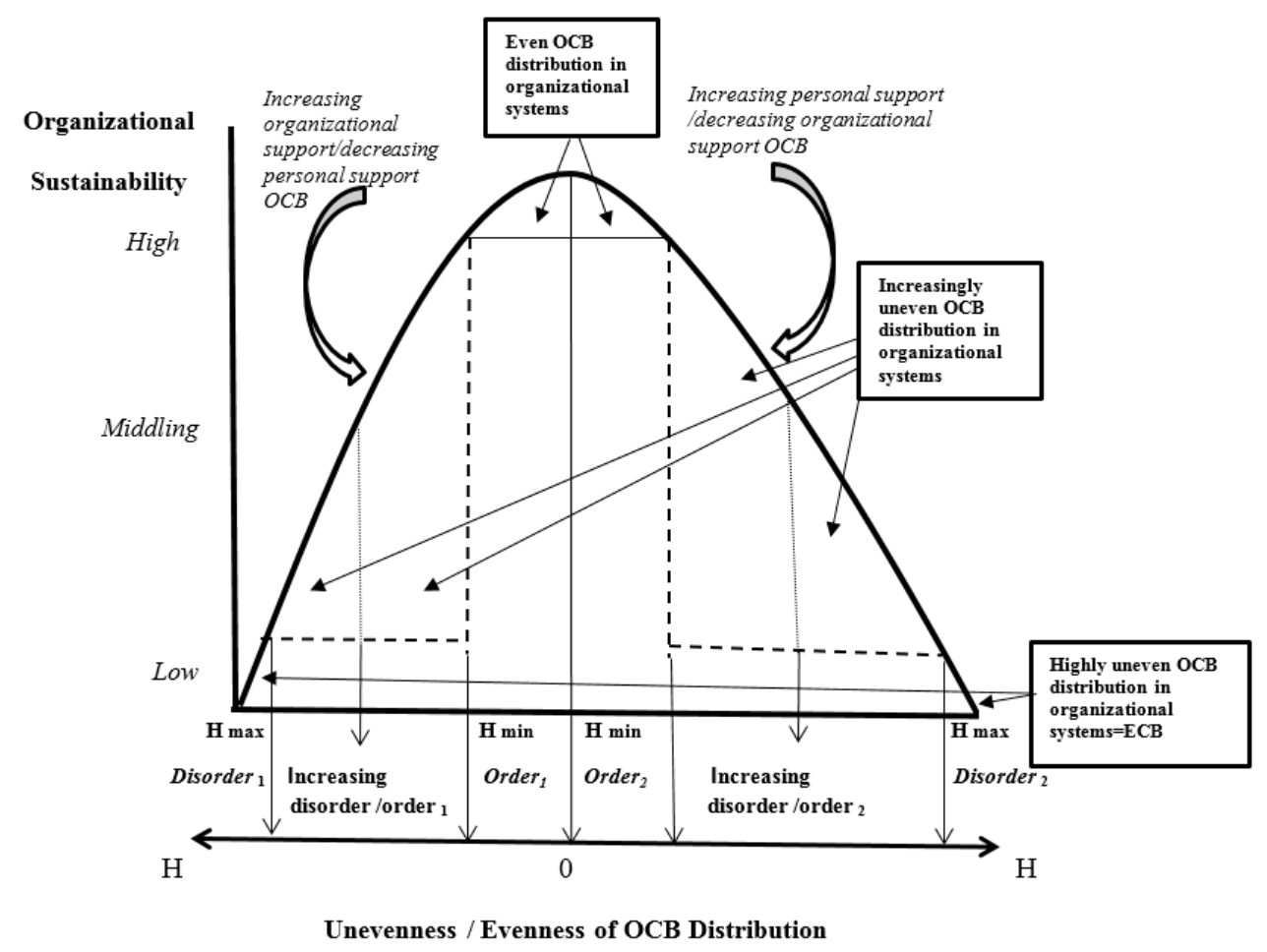

Figure 1. A diagrammatic representation of OCB, ECB and organizational sustainability.

\section{Conclusions}

There can be little doubt that organizations depend on citizenship-type behavior for their continued existence and long-term sustainability. The importance of this aspect is clearly manifested when organizations are confronted by "work-to-rule" situations where employees do only as much as their formal job descriptions require of them, seriously undermining their productivity and the organization's efficiency. It is also evident from the secondary data reviewed, that extreme forms of OCB can lead to organizational systems' entropy, threatening the on-going sustainability of individual organizations and the urban organizational systems in which they are embedded. Also, Fistola [44] has clearly shown the propensity of a singular urban subsystem entropy in generating entropy in other urban subsystems and, through a process of deconstruction in entropic clusters which systematically remove energy necessary for their survival, ultimately undermine the sustainability of urban systems as a whole. The model proposed in the paper suggests how OCB and OCE can be more accurately measured in organizational systems using an approach based on Theil's earlier work. The study uses eclectic secondary data only to build the tentative model and it is recommended that further research in the area should test the validity of the model more fully using primary research data as its core research focus. Empirical measurement of the effects of the OCE as a singular entropy generator might then be assessed in terms of its urban subsystem ripple effects and, ultimately, its effect on the urban system as a whole.

Acknowledgments: The research was funded by the National Research Foundation of South Africa and The University of the Witwatersrand.

Conflicts of Interest: The authors declare no conflict of interest.

\section{References}

1. Bailey, K.D. Social entropy theory: An overview. Syst. Pract. 1990, 3, 365-382. [CrossRef]

2. Clausius, R. The Mechanical Theory of Heat: With Its Applications to the Steam-Engine and to the Physical Properties of Bodies; J. Van Voorst: London, UK, 1867; p. 376. 
3. Carrier, B. Entropy Explained The Secular Web. Available online: http://infidels.org/library/modern/ richardcarrier/entropy.html (accessed on 15 July 2016).

4. Boltzman, L. Lectures on Gas Theory; University of California: Berkley, CA, USA, 1964.

5. Chakrabarti1, C.G.; Chakrabarty, I. Boltzmann Entropy: Probability and Information. Available online: https://arxiv.org/ftp/arxiv/papers/0705/0705.2850.pdf (accessed on 3 August 2016).

6. Shannon, C.E. A mathematical theory of communication. Bell Syst. Tech. J. 1948, 27, 379-423. [CrossRef]

7. Gell-Mann, M. El Quark y el Jaguar; Océano/Tusquets: Madrid, Spain, 1995.

8. Theil, H. Statistical Decomposition Analysis; North-Holland Publishing Company: Amsterdam, The Netherlands, 1972.

9. Landsberg, P. Is equilibrium always an entropy maximum? J. Stat. Phys. 1984, 35, 159-169. [CrossRef]

10. Gunn, B. The dynamic synthesis theory of motivation. Manag. Sci. 1968, 14, B106-B619. [CrossRef]

11. Le Chatelier, H. Recherches Experimentaleset Theoriquessur les Equilibres Chimiques (Experimental and Theoretical Research on Chemical Equilibria); Annales des Mines, Hutieme Serie, Memiories, XIII; Dunod: Paris, France, 1888.

12. Ackoff, R.L. Creating the Corporate Future: Plan or be Planned for; Wiley: New York, NY, USA, 1981.

13. DeMarco, T.; Lister, T. Peopleware: Productive Projects and Teams, 2nd ed.; House Pub: Dorset, UK, 1999.

14. Williams, B. Defining Organizational Entropy. Available online: http://merchantstand.com/2010/01/ defining-organizational-entropy $/ 13$ (accessed on 8 September 2016).

15. Martínez-Berumena, H.A.; López-Torresa, G.C.; Romo-Rojasa, L. Developing a Method to Evaluate Entropy in Organizational Systems. Procedia Comput. Sci. 2014, 28, 389-397. [CrossRef]

16. Lara Rosano, F. Cibernética y sistemas cognitivos. In Ingeniería de Sistemas, Alfaomega; Alfaomega-UNAM: Mexico City, Mexico, 2002.

17. Simon, H.A. The organization of complex systems. In Hierarchy Theory. The Challenge of Complex Systems; Pattee, H.H., Ed.; Braziller: New York, NY, USA, 1973; pp. 1-27.

18. Organ, D. Organizational Citizenship Behavior: The Good Soldier Syndrome; Lexington Books: Lexington, MA, USA, 1988.

19. Organ, D. A reappraisal and reinterpretation of the satisfaction-causes performance hypothesis. Acad. Manag. Rev. 1977, 2, 46-53.

20. Borman, W. The concept of organizational citizenship. Curr. Dir. Psychol. Sci. 2004, 13, 238-241. [CrossRef]

21. Nielsen, T.; Hrivnak, G.; Shaw, M. Organizational citizenship behavior and performance: A meta-analysis of group-level research. Small Group Res. 2009, 40, 555-577. [CrossRef]

22. Sevi, E. Effects of organizational citizenship behaviour on group performance: Results from an agent-based simulation model. J. Mod. Manag. 2010, 5, 25-37. [CrossRef]

23. Coldwell, D.A.L.; Callaghan, C. Specific organizational citizenship behaviours and organizational effectiveness: The development of a conceptual heuristic device. J. Theory Soc. Behav. 2014, 44, 347-367. [CrossRef]

24. Axelrod, R. An evolutionary approach to norms. Am. Political Sci. Rev. 1986, 80, 1095-1111. [CrossRef]

25. Forquer, J. The Kamikaze: A New Appraisal. Available online: http://www.globalsecurity.org/military/ library/report/1995/FJA.htm (accessed on 1 August 2012).

26. Allen, M. Ricola Boss Confessed Fraud before Suicide. Available online: http:/ /www.swissinfo.ch/eng/ business/2011 (accessed on 1 August 2012).

27. Ayres, R.U.; van den Bergh, J.; Gowdy, J.M. Viewpoint: Weak versus Strong Sustainability. Center for the Management of Environmental Resources. 1998. Available online: http://dspace.ubvu.vu.nl/bitstream/ handle/1871/9295/98103.pdf?sequence $=1$ (accessed on 11 August 2016).

28. Gowdy, J.M.; McDaniel, C. The physical destruction of Nauru: An example of weak sustainability. Land Econ. 1999, 75, 33-38. [CrossRef]

29. Neumayer, E. Weak versus Strong Sustainability: Exploring the Limits of Two Opposing Paradigms; Elgar: London, UK, 2003.

30. Davies, G.R. Appraising weak and strong sustainability: Searching for a middle ground. Consilience 2013, 10, $111-124$.

31. Solow, R. The economics of resources and the resources of economics. Am. Econ. Rev. 1974, 64, 1-14.

32. Solow, R. On the intergenerational allocation of natural resources. Scand. J. Econ. 1986, 88, 141-149. [CrossRef]

33. Solow, R. An almost practical step toward sustainability. Resour. Policy 1993, 2, 162-172. [CrossRef] 
34. Hartwick, J. Intergenerational equity and the investing of rents from exhaustible resources. Am. Econ. Rev. 1977, 67, 972-974.

35. Hartwick, J. Substitution among exhaustible resources and intergenerational equity. Rev. Econ. Stud. 1978, 45, 347-354. [CrossRef]

36. Hartwick, J. Natural resource accounting and economic depreciation. J. Public Econ. 1990, 43, $291-304$. [CrossRef]

37. Baker, S. Sustainable Development; Routledge: Abingdon, Australia, 2006.

38. Carson, R. Silent Spring; Penguin Books: London, UK, 1962.

39. Shute, N. On the Beach; Heinemann: Sydney, Australia, 1957.

40. Heylighen, F. Representation and Change. A Metarepresentational Framework for the Foundations of Physical and Cognitive Science; Communication \& Cognition: Ghent, Belgium, 1990; p. 200.

41. Beer, S. Diagnosing the System for Organizations; John Wiley: London, UK, 1985.

42. Wanniski, J. Taxes, Revenues and the 'Laffer Curve'. Available online: http://www.nationalaffairs.com/ doclib/20080528_197805001taxesrevenuesandthelaffercurvejudewanniski.pdf (accessed on 23 August 2012).

43. Iceland, J. The Multigroup Entropy Index (Also Known as Theil's H or the Information Theory Index). Available online: https://www.census.gov/housing/patterns/about/multigroup_entropy.pdf (accessed on 23 August 2016).

44. Fistola, R. Urban Entropy vs. Sustainability: A New Town Planning Perspective. WIT Transactions on Ecology and the Environment. 2012, vol. 155. Available online: https://www.witpress.com (accessed on 9 December 2016).

45. Cabral, P.; Augusto, G.; Tewolde, M.; Araya, Y. Entropy in urban systems. Entropy 2013, 15, 5223-5236. [CrossRef]

(C) 2016 by the author; licensee MDPI, Basel, Switzerland. This article is an open access article distributed under the terms and conditions of the Creative Commons Attribution (CC-BY) license (http://creativecommons.org/licenses/by/4.0/). 